\title{
MORPHOLOGIC QUALITY OF DSMs BASED ON OPTICAL AND RADAR SPACE IMAGERY
}

\author{
Sefercik, U. G.*, Bayik, C.*, Karakis, S.*, Jacobsen, K.** \\ * Zonguldak Karaelmas University \\ ugsefercik@hotmail.com \\ ** Leibniz University Hannover \\ jacobsen@ipi.uni-hannover.de
}

KEY WORDS: DSM, SPOT-5, SRTM C-band, ASTER GDEM, Morphologic quality, Comparison

\begin{abstract}
:
Digital Surface Models (DSMs) are representing the visible surface of the earth by the height corresponding to its X-, Y-location and height value $\mathrm{Z}$. The quality of a DSM can be described by the accuracy and the morphologic details. Both depend upon the used input information, the used technique and the roughness of the terrain.

The influence of the topographic details to the DSM quality is shown for the test fields Istanbul and Zonguldak. Zonguldak has a rough mountainous character with heights from sea level up to $1640 \mathrm{~m}$, while Istanbul is dominated by rolling hills going up to an elevation of 435m. DSMs from SPOT-5, the SRTM C-band height models and ASTER GDEM have been investigated.

The DSMs have been verified with height models from large scale aerial photos being more accurate and including morphologic details. It was necessary to determine and respect shifts of the height models caused by datum problems and orientation of the height models. The DSM quality is analyzed depending upon the terrain inclination.
\end{abstract}

The DSM quality differs for both test fields. The morphologic quality depends upon the point spacing of the analyzed DSMs and the terrain characteristics.

\section{INTRODUCTION}

Digital Surface Models (DSMs) are the three dimensional (3D) presentation of the visible Earth surface including entire objects like buildings, roads, vegetation, forest etc. among bare topography. They are a basic element for the analysis of several kinds of engineering disciplines. To satisfy this need, various DSM generation techniques have been improved. Every technique has advantages and disadvantages against each other and the final products are different. At this point, the DSM quality has to be mentioned. The accuracy and the morphologic details are the most important components describing the DSM quality.

In this paper, the qualities of SPOT-5 HRS, ASTER GDEM and SRTM DSMs have been analyzed at two different test fields (Istanbul and Zonguldak) in Turkey which have different topographic characteristics. At both test fields, more accurate reference Digital Elevation Models (DEMs) produced by photogrammetry have been used for the accuracy analysis.

\section{TEST FIELDS}

\subsection{Historical Peninsula, Istanbul}

The test area Historic Peninsula Istanbul covers $10 \mathrm{~km} \times 8 \mathrm{~km}$. It includes the historical peninsula and near surroundings. Historic Peninsula (Old City) is one of the most important regions in Istanbul, located on the European side, surrounded by the Bosporus and Marmara Sea. This part is important because of its historic heritage. Figure 1 shows the landscape of test field with the frequency distribution of terrain inclination. The elevation reaches from sea level up to $130 \mathrm{~m}$.
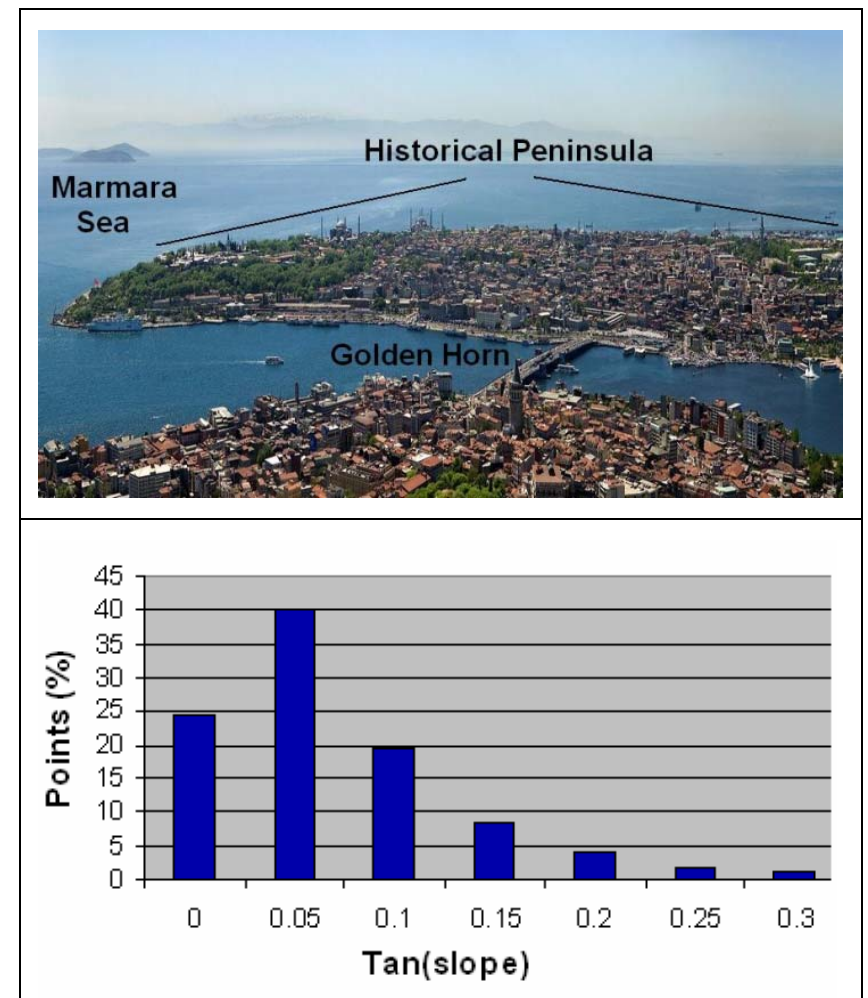

Figure 1. Historical Peninsula and the frequency distribution of terrain inclination 


\subsection{Zonguldak}

The test area Zonguldak is located in west Black Sea region at the north-west part of Turkey. The city has a very steep and mountainous topography with terrain inclination up to $45^{\circ}$ (figure 2), partially also vertical cliffs. The rough terrain as it can be seen in figure 2 causes problems for image matching, but also lay-over of the SRTM Synthetic Aperture Radar.
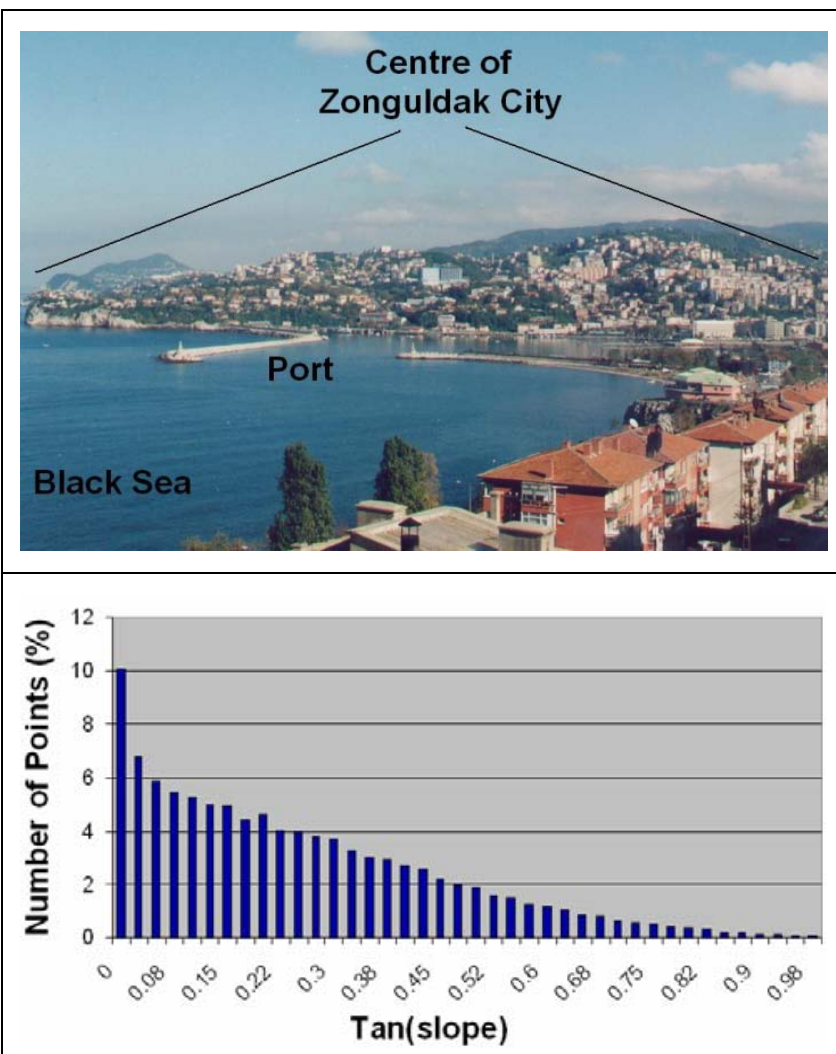

Figure 2. Zonguldak City and the frequency distribution of terrain inclination

\section{DATA SETS}

\subsection{Reference Data}

\section{Historic Peninsula Istanbul}

The reference DEM of Historic Peninsula was derived from 1:1000 scale digital photogrammetric maps by a project of Greater Istanbul Municipality. This DEM was generated between 2007 and 2009. The original grid spacing of the DEM is $5 \mathrm{~m}$ and has a standard deviation from $10 \mathrm{~cm}$ up to $1 \mathrm{~m}$. Figure 3 (upper side) illustrates this reference DEM. It is named following as REFHISPEN.

\section{Zonguldak}

The reference DEM of Zonguldak was also achieved from 1:1000 scale digital photogrammetric maps by a project of Zonguldak Municipality. It was generated in 2005 with $10 \mathrm{~m}$ grid spacing and has also $10 \mathrm{~cm}$ up to $1 \mathrm{~m}$ accuracy. Figure 3 (lower side) shows this reference DEM. This DEM is named following as REFZDAK.

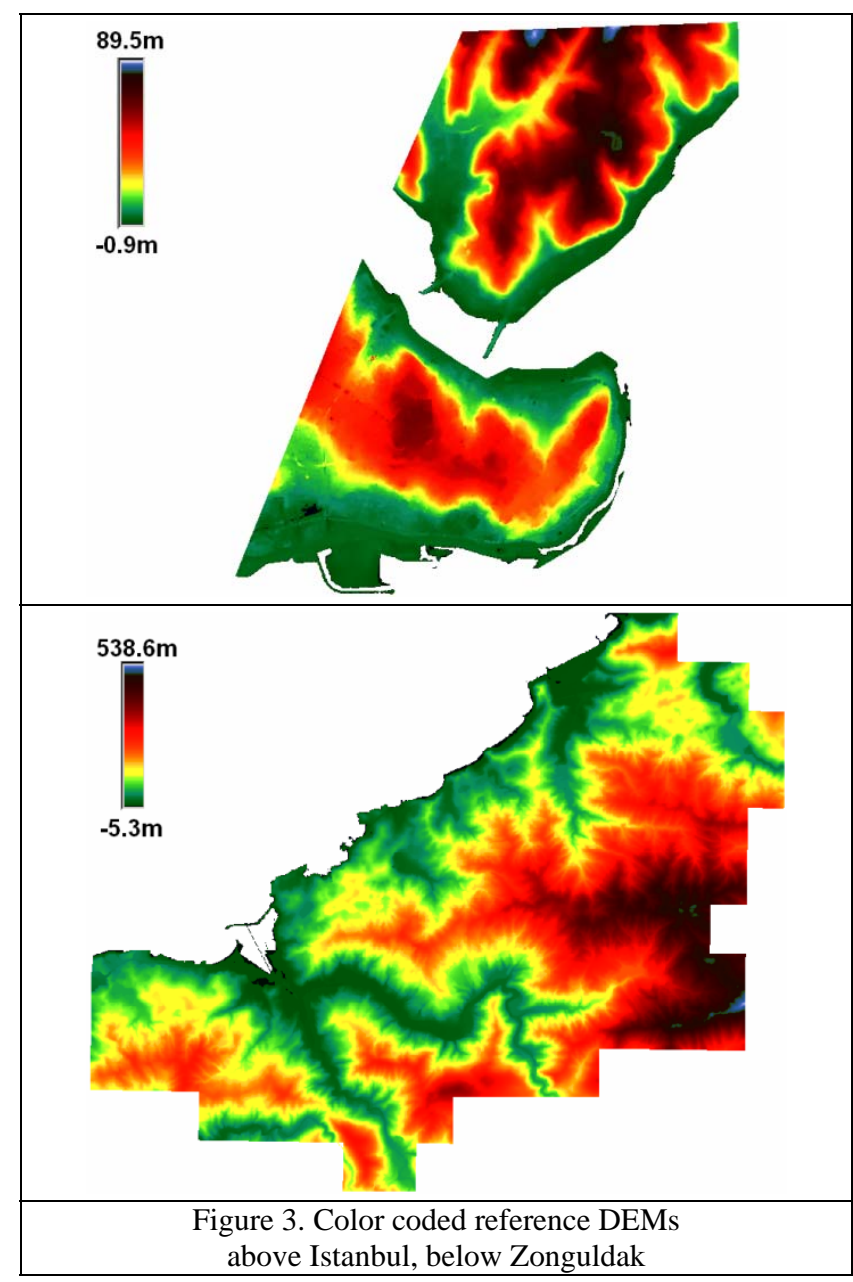

\subsection{SPOT-5 HRS DSM}

SPOT-5 was launched to its orbit in May 2002 along with Ariane 4 launch vehicle from Europe's spaceport in Kourou, French Guiana. In addition to the major HRG instruments SPOT 5 has also the High Resolution Stereoscopic instrument (HRS) with two telescopes, acquiring stereo pairs at a 90second interval, of $120-\mathrm{km}$ swath, along the track of the satellite, with a b/h ratio of about 0.8 (Baudoin et al, 2003). The HRS instrument has been designed for a ground sampling distance of 5 meters along the track. In a direction close to the epipolar planes, this along-track over-sampling allows higher altimetric accuracy of the DEM to be obtained (Michalis and Dowman 2004). The SPOT-5 HRS DSMs of test fields used in this study are in $20 \mathrm{~m}$ grid spacing. Figure 4 shows the SPOT-5 HRS DSMs of Istanbul and Zonguldak sequentially at the upper and lower part respectively.

\subsection{ASTER GDEM}

The optical satellite ASTER (Advanced Spaceborne Thermal Emission and Reflection Radiometer) has been launched to its orbit in December, 1999 by NASA. The satellite is capable to along-track stereoscopy. It used two telescopes in its near infrared spectral band to acquire data from nadir and backward views and collected over 1.2 million scenes in a global coverage (North $83^{\circ}$ to South $83^{\circ}$ ) between March 2000 and August 2008 (temporal coverage between January 2000 and June 2008). Using the entire ASTER stereo-optical images, a Global DSM was generated in early 2009. This DSM has 1 arcsecond $(\sim 30 \mathrm{~m})$ 
posting interval. Figure 5 shows the ASTER GDEM of both test fields.
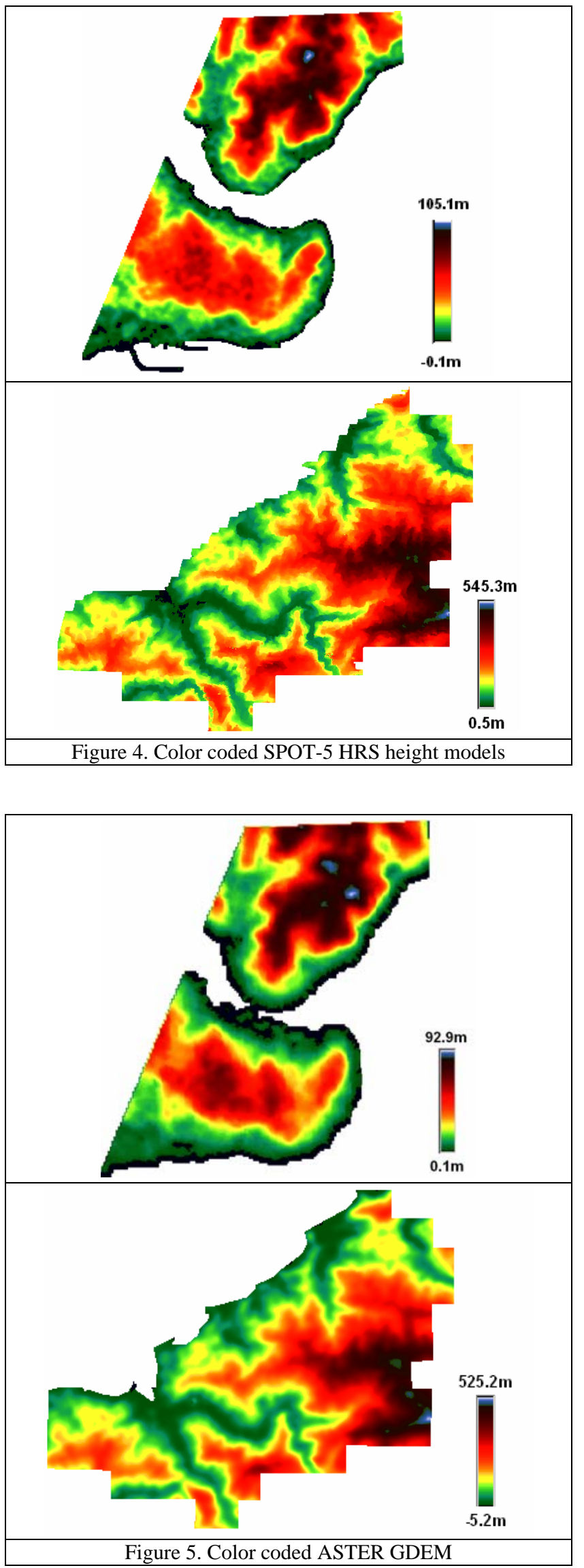

\subsection{SRTM C and X-band DSMs}

SRTM has been flown in February 2000 to generate high resolution, near-global DSMs $\left(60.25^{\circ}\right.$ northern and $56^{\circ}$ southern latitude). The radar sensors have been on board the space shuttle Endeavour for 11 days. SRTM was a joint project between American National Aeronautics Space Administration (NASA) and the National Imagery and Mapping Agency (NIMA) in cooperation with German Aerospace Centre DLR and Italian Space Agency. The data acquisition system of the shuttle used single-pass interferometric SAR technique. SRTM carried two different types of antennas. One of them, the main antenna was located at the cargo bay of the shuttle having a length of $12 \mathrm{~m}$, transmitting and receiving. The other one, outboard antenna was located at the end of a $60 \mathrm{~m}$ long mast and was only receiving. American C-band and German/Italian X-band were used at the mission. The shuttle had $233 \mathrm{~km}$ orbital height and $57^{\circ}$ orbit inclination. The American C-band operated with a wavelength of $5.6 \mathrm{~cm}$. With the C-band, having $225 \mathrm{~km}$ wide swath, 119.51 million square $\mathrm{km}$ were imaged corresponding to $99.97 \%$ of the target area with originally 1 arcsecond (nearly $31 \mathrm{~m}$ at the equator) point-spacing. $94.6 \%$ of the mapped area was covered at least twice and approximately $50 \%$ at least three times. The full resolution height models are available only inside the USA while outside the USA the point spacing is reduced to 3 arcsec. These height models are available free of charge (Sefercik, 2010).

The German/Italian X-band operated with $45 \mathrm{~km}$ swath width and a wavelength of $3 \mathrm{~cm}$. Depending on this shorter wavelength its relative vertical accuracy by theory is higher than for the Cband. X-band provided 1 arcsecond (nearly $30 \mathrm{~m}$ at the equator) spacing data, but not free of charge. This smaller point-spacing has several benefits. For example, the difference in spacing is important for interpolation in mountainous areas. In the mountainous area of Zonguldak the interpolation may cause a loss of accuracy nearly by the factor of 2.0 for 3 arcsec point spacing but for the smaller spacing of the X-band data only a loss of accuracy in the range of $20 \%$ (Sefercik and Jacobsen 2007).

Like SAR, also InSAR has problems with lay-over and foreshortening especially in the partially steep area of Zonguldak. This can be seen in the coherence map, in the case of the SRTM X-band delivered together with the height model as height error map (HEM) with estimated point accuracy (figure 6).

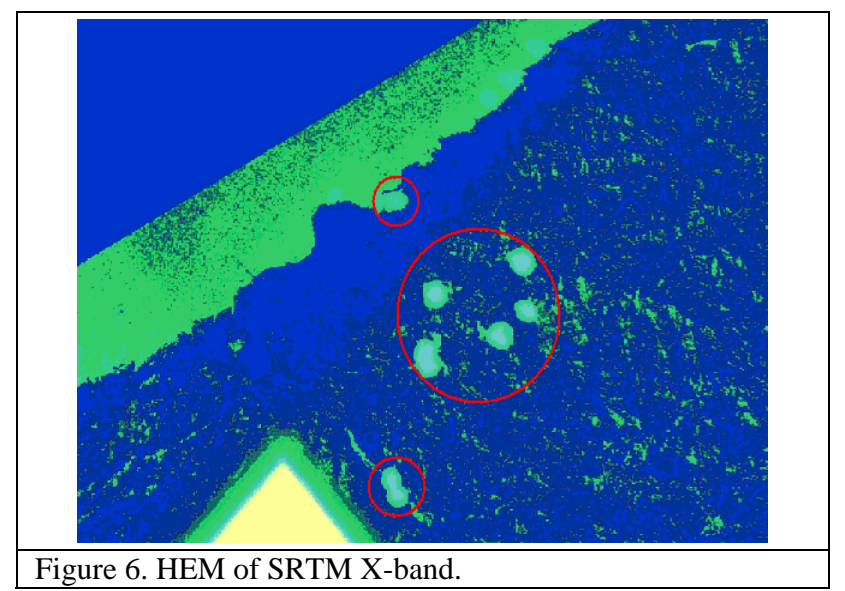

The red circles show areas with problems caused by large terrain inclination. The upper circle covers a steep build up area. 
The areas indicated by the X-band HEM are confirmed by larger discrepancies against the reference height model. The DSMs of SRTM C- and X-bands of Zonguldak (figure 7) and the C-band for Istanbul (figure 8) can be seen below. SRTM Xband DSM was not achieved for Istanbul.

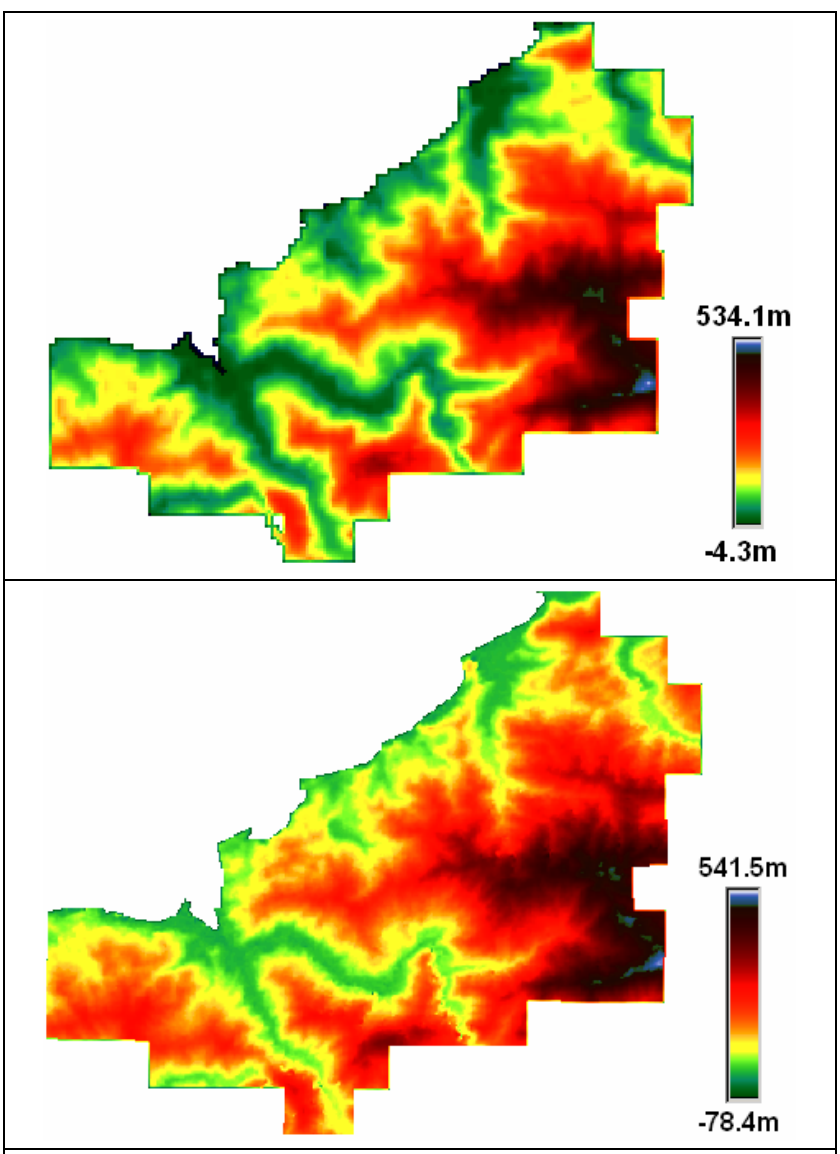

Figure 7. SRTM C- and X-band height model of Zonguldak

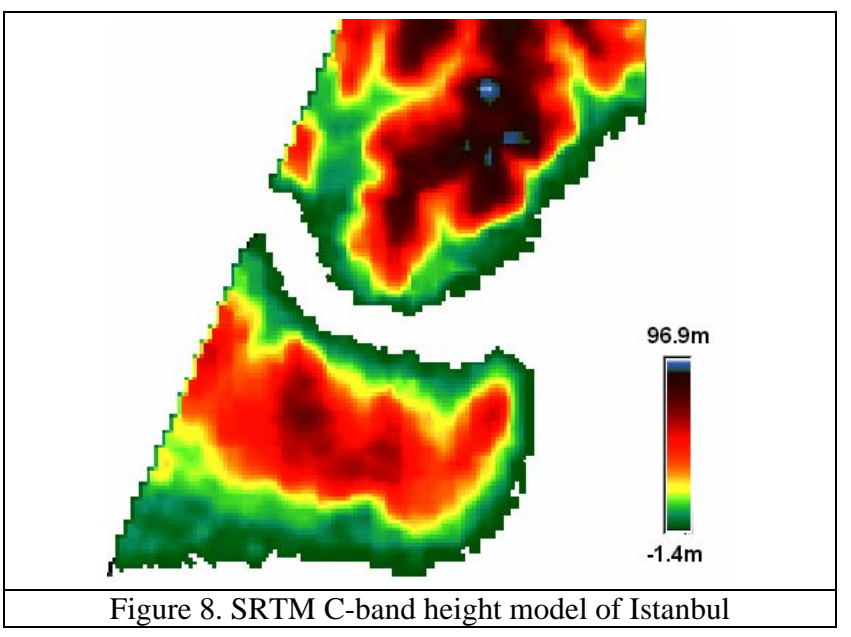

\section{ACCURACY ANALYSIS}

The quality of a DEM can be assessed by various procedures. The standard procedure is the comparison with a reference DEM. For the accuracy analysis the evaluated DSMs have to be in same coordinate system as the reference. Therefore, the horizontal shifts between height models caused by not precise known datum of national coordinate systems against the WGS84 / ITRF used by SRTM and ASTER GDEM has to be eliminated. The shift of the height models to the reference models has been determined by adjustment with the Hannover program DEMSHIFT. The effect of shifting can be seen in Tables 1 and 2.

\begin{tabular}{|l|c|c|c|}
\hline & $\begin{array}{c}\text { SPOT } \\
\text { HRS }\end{array}$ & $\begin{array}{c}\text { ASTER } \\
\text { GDEM }\end{array}$ & $\begin{array}{c}\text { SRTM } \\
\text { C-band }\end{array}$ \\
\hline before shift & $13.31 \mathrm{~m}$ & $12.78 \mathrm{~m}$ & $8.28 \mathrm{~m}$ \\
\hline after shift & $5.30 \mathrm{~m}$ & $5.78 \mathrm{~m}$ & $4.46 \mathrm{~m}$ \\
\hline \multicolumn{2}{|l|}{ Table 1: root mean square height differences in relation to the } \\
REFHISPEN before and after horizontal shift \\
\hline
\end{tabular}

\begin{tabular}{|l|c|c|c|c|}
\hline & $\begin{array}{c}\text { SPOT } \\
\text { HRS }\end{array}$ & $\begin{array}{c}\text { ASTER } \\
\text { GDEM }\end{array}$ & $\begin{array}{c}\text { SRTM } \\
\text { X-band }\end{array}$ & $\begin{array}{c}\text { SRTM } \\
\text { C-band }\end{array}$ \\
\hline before shift & $25.42 \mathrm{~m}$ & $13.15 \mathrm{~m}$ & $15.70 \mathrm{~m}$ & $24.94 \mathrm{~m}$ \\
\hline after shift & $8.73 \mathrm{~m}$ & $9.83 \mathrm{~m}$ & $6.59 \mathrm{~m}$ & $10.69 \mathrm{~m}$ \\
\hline \multicolumn{5}{|l}{ Table 2: root } \\
REFZDAK square height differences in relation to the \\
Refore and after horizontal shift
\end{tabular}

The root mean square height differences of the evaluated DSMs against the reference height models are depending upon the terrain inclination. By this reason the accuracy has to be described by a constant value plus a constant value multiplied with the tangent of the terrain inclination. This relation is determined by adjustment with program DEMANAL.

\begin{tabular}{|l|c|}
\hline DSM & General \\
\hline SPOT-5 HRS & $5.05+0.1 \times \tan \alpha$ \\
\hline ASTER GDEM & $4.75+8.9 \times \tan \alpha$ \\
\hline SRTM C-band & $4.25+6.6 * \tan \alpha$ \\
\hline $\begin{array}{l}\text { Table 3: root mean square height differences against } \\
\text { REFHISPEN [m] as function of the terrain inclination } \alpha\end{array}$ \\
\hline
\end{tabular}

\begin{tabular}{|l|c|}
\hline DSM & General \\
\hline SPOT-5 HRS & $3.81+8.0 * \tan \alpha$ \\
\hline ASTER GDEM & $8.86+1.5 * \tan \alpha$ \\
\hline SRTM X-band & $4.13+3.7 * \tan \alpha$ \\
\hline SRTM C-band & $7.42+6.2 * \tan \alpha$ \\
\hline $\begin{array}{l}\text { Table 4: root mean square height differences against } \\
\text { REFZDAK [m] as function of the terrain inclination } \alpha\end{array}$ \\
\hline
\end{tabular}

The accuracy of the SPOT-5 HRS and ASTER height models have to be seen in relation to the GSD, the height to base relation and the standard deviation of the $x$-parallax leading to: $\mathrm{SZ}=\mathrm{h} / \mathrm{b} * \mathrm{Spx}$. The standard deviation of the $\mathrm{x}$-parallax in units of the GSD can compared between quite different optical sensors. For open and flat terrain the standard deviation of the x-parallax of SPOT-5 corresponds to 0.31GSD while it is $0.23 G S D$ for ASTER. In Istanbul, the better accuracy for ASTER can be explained by the advantage of the near infrared spectral band used for the stereo combination (Sefercik and Jacobsen, 2007). However, at the steep and mountainous test field, Zonguldak, SPOT and SRTM C and X-band DSMs have better accuracy against ASTER. On the other hand, the accuracy of SRTM X-band height model is better than C-band height model because of grid spacing. With 1 arcsecond the description of the topography closer to reality as with 3 arcsecond point spacing.

\section{MORPHOLOGIC QUALITY}

The morphologic quality analysis is an important step of the height model evaluation. This is another way to understand the 
relative accuracy of a height model. Base of this application is the shape of contour lines. The most important factor is the grid spacing required for the details of the contour lines. If the grid spacing of a height model is larger, fewer points can be used for the generation of contour lines, causing smoother lines. Figure 9 and 10 illustrate the contour lines generated from evaluated DSMs sequentially for Istanbul and Zonguldak test fields. An equidistance of $20 \mathrm{~m}$ is chosen for test field Istanbul and $100 \mathrm{~m}$ for test field Zonguldak for better visual representation.

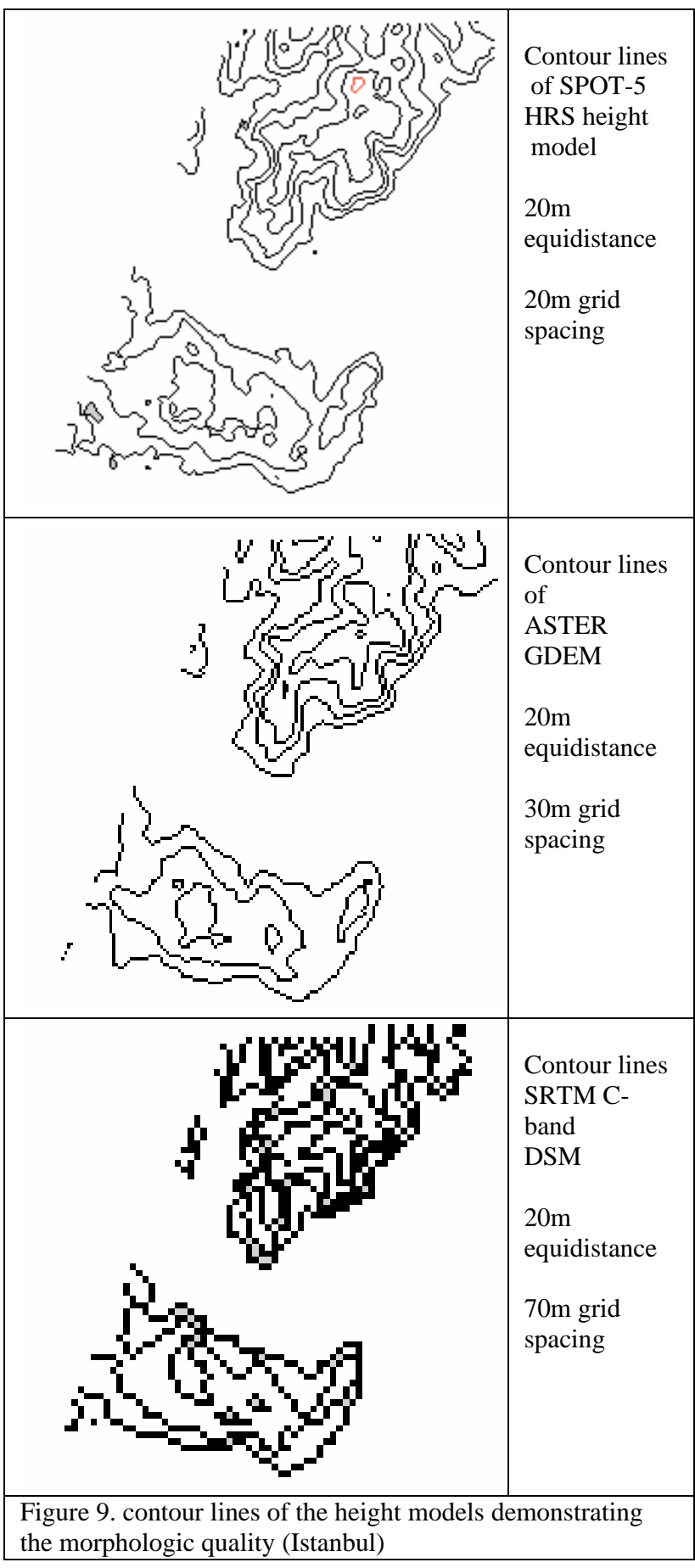

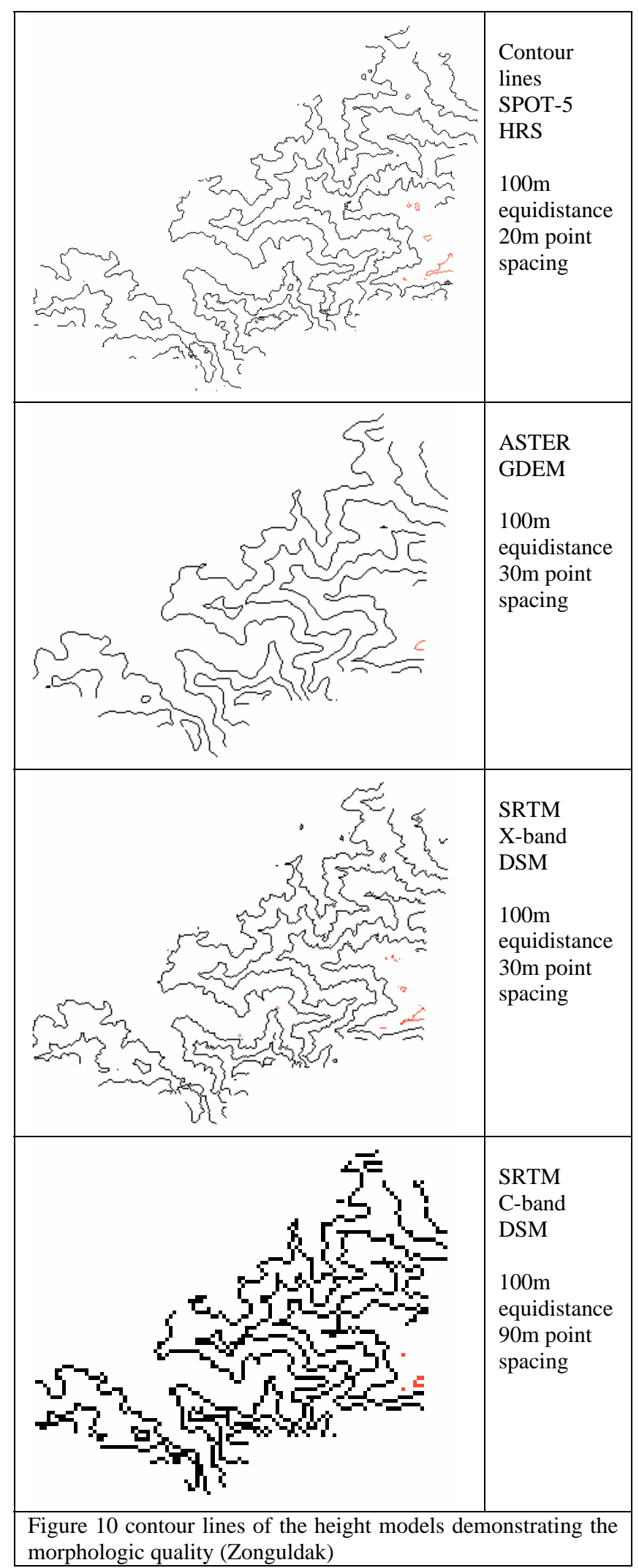

As it can be seen from above figures, the structure of contour lines generated from SPOT-5 HRS is more detailed. The comparison of ASTER GDEM and SRTM X-band DSM is very interesting because the SRTM X-band contour lines are more detailed than ASTER contour lines even if they have similar grid spacing. ASTER GDEM contour lines are smoother. As 
expected, the quality of contour lines generated from SRTM Cband is lower than the others caused by the large point spacing.

\section{CONCLUSION}

Digital surface models can be generated by automatic matching of optical stereo models as well by InSAR. Their quality depends upon various parameters as the topographic characteristics of the used area. Istanbul and Zonguldak test fields were used which have different topographic characteristics. If the terrain inclination is large as in Zonguldak, the collection of qualified data becomes more difficult. ASTER GDEM and SRTM C-band DSMs have lower accuracy in Zonguldak as in Istanbul. The grid spacing of the DSMs is essential for the morphologic quality. The contour lines generated from SPOT-5 HRS data are better as from ASTER GDEM and SRTM C-band. On the other hand, contour lines of SRTM X-band DSM are very close to SPOT-5.

\section{ACKNOWLEGMENTS}

Thanks are going to DLR, Germany, TUBITAK, Turkey, METI, NASA and the Municipalities of Istanbul and Zonguldak for the supports of this research.

\section{REFERENCES}

Baudoin A., Schroeder M., Valorge C., Bernard M. and Rudowski V., 2003. The HRS SAP initiative: A scientific assessment of the High Resolution Stereoscopic instrument on board of SPOT 5 by ISPRS investigators, ISPRS Hannover Workshop, High Resolution Mapping from Space, Hannover, Germany.

Michalis P. and Dowman I., 2004. A Rigorous Model and DEM Generation for SPOT-5 RS, ISPRS Congress, Istanbul, Turkey.

Sefercik U. G. and Jacobsen K., 2007. Quality Assessment of InSAR Digital Elevation Models, 27 EARSeL Symposium "Geoinformation in Europe" 4-9 June, Bolzano, Italy

Sefercik U. G., Jacobsen K., Oruc M., Marangoz A., 2007. Comparison of SPOT, SRTM and ASTER DEMs, ISPRS Hannover Workshop 2007 High-Resolution Earth Imaging for Geospatial Information, 29 May-1 June, Hannover, Germany.

Sefercik U. G., 2010. Generation and Evaluation of TerraSARX InSAR Images, PhD Thesis, June 2010, Zonguldak Karaelmas University. 